\title{
ENTRE JESI E PAVESE TEMPO FESTIVO COMO ATO DE RESISTÊNCIA
}

\section{Davi Pessoa Carneiro}

UERJ

RESUMO: 0 presente ensaio aborda algumas questões sobre mito e tempo festivo no pensamento de Furio Jesi e Cesare Pavese, assim como na reflexão de Jesi sobre a presença-ausência da festa na trilogia de Pavese. A perda da possibilidade de aceder à festa passa a ser 0 ato de criação e de resistência, a potência-de-não, tal como discutida pelo filósofo Giorgio Agamben. Em última análise, a máquina mitológica e a inoperosidade coincidem, portanto, com a própria festividade, com 0 "fazer a festa", com o sacrifício e com o desativar e tornar inoperosos os gestos, as ações e as obras humanas.

PALAVRAS-CHAVE: Mito. Tempo festivo. Ato de criação. Inoperosidade.

\section{BETWEEN JESI AND PAVESI FESTIVE TIME AS ACT OF RESISTANCE}

ABSTRACT: The present essay is focused on some questions about myth and festive time in the thought of Furio Jesi and Cesare Pavese, as well as, in the reflection of Jesi about the presenceabsence of feast in Pavese's trilogy. The loss of the possibility of access the feast becomes the act of creation and resistance, the potency-of-no, in the same way it is discussed by the philosopher Giorgio Agamben. Thus, in the last analysis, the mythological and the inoperosity coincide with the festivity, with the "having the feast", with the sacrifice and with the deactivating and making inoperose the human gestures, the actions and the works.

KEYWORDS: Myth. Festive time. Act of creation. Inoperosity.

Davi Pessoa Carneiro é tradutor e professor adjunto de língua e literatura italiana na Universidade do Estado do Rio de Janeiro. 


\title{
ENTRE JESI E PAVESE TEMPO FESTIVO COMO ATO DE RESISTÊNCIA
}

Davi Pessoa Carneiro

Furio Jesi (1941-1980) dedicou-se por alguns anos de sua breve existência ao estudo do mito. $O$ mito, segundo Jesi, não significa a transcendência de um objeto conhecido nem o reenvio, diante do objeto a ser conhecido, a algo que o transcenda. O mito, portanto, é desprovido de transcendência; é um agir, ou seja, uma operação em palavras ou em imagens. O mito, do mesmo modo, traz em si uma ambivalência. Jesi segue os rastros de tal ambivalência, por exemplo, nos escritos de Cesare Pavese, Rilke, Rimbaud, a saber:

\begin{abstract}
O mito em sua milenária realidade histórica é a história verdadeira por excelência e a história falsa por excelência, a narrativa da verdade que não necessita absolutamente de motivações e a fábula à qual não se pedem motivações, pois não é verdadeira. ${ }^{1}$
\end{abstract}

O mito, assim, é um fluir, e continua a fluir independentemente do fato que os homens reconheçam nele o paradigma do necessariamente verdadeiro ou do naturalmente falso, e ainda, ambivalentemente, o mito "tem a impassibilidade dos deuses, mas também das coisas finitas que existem mesmo morrendo no momento em que nascem." ${ }^{2}$

É importante destacar que, para Jesi, não existe uma substância do mito, mas, sim, uma máquina que produz mitologias. A máquina mitológica é uma sorte de labirinto, como sagazmente a concebe Giorgio Agamben, no ensaio "Sull'impossibilità di dire io. Paradigmi epistemologici e paradigmi poetici in Furio Jesi", isto é, um sofisticado mecanismo apotropaico, visto que "interioriza aquilo que mantém a distância." ${ }^{3}$ A máquina mitológica, assim, mantém

\footnotetext{
${ }^{1} \mathrm{JESI}$, Furio. Mito e non conoscere. Riga, Milano, n. 31, p. 92, 2010.

2 Ibidem, p. 92.

${ }^{3}$ AGAMBEN, Giorgio. Sull'impossibilità di dire io. Paradigmi epistemologici e paradigmi poetici in Furio Jesi. Riga, Milano, n. 31, p. 147, 2010. O texto foi publicado originalmente em Cultura Tedesca, Roma, n. 12, p. 11-20, 1999; depois em AGAMBEN, Giorgio. La potenza del pensiero. Vincenza: Neri Pozza, 2005.
} 
duas forças ambivalentes num duelo constante, capaz até mesmo de envolver o eu do autor de modo dramático em sua possibilidade e impossibilidade de dizer eu. Isto é, o sujeito não basta vir ao mundo, mas precisa se apresentar, porém na medida em que tal operação se põe em movimento uma distância se interpõe, e o eu que a priori articulava seu discurso com segurança se confronta com outro eu que não apenas se sente inseguro, mas que coloca em dúvida sua própria existência. Agamben, no ensaio citado, faz referência ao segundo projeto de prefácio para a seleção de textos de La macchina mitologica (1979), em que Jesi argumenta a complicada operação mimético-teatral em questão. Segundo Jesi:

O eu que está "seguro" realiza seu discurso, neste livro, com o eu que não somente não está seguro, mas que tem uma grande suspeita que jamais estará. $\mathrm{Na}$ base da técnica de conhecimento por composição se encontra esse cruzamento de duas vozes, que não pode ser definido dialético senão na medida em que "dialético" significa puramente e simplesmente "dramático". 4

Para Agamben, a máquina mitológica é um recalque ou uma máscara do eu, ou melhor, uma "dramatização ou uma teatralização em duas vozes do sujeito, de seu ritmo interior e de sua íntima cisão", e, ainda, "coincide com sua possibilidade ou impossibilidade de dizer eu". ${ }^{5}$

Nesse caso, seria melhor substituir a adversativa "ou" pela conjunção aditiva "e", visto que a possibilidade $e$ a impossibilidade de dizer eu ocorrem no mesmo instante. Tal como no labirinto, essas duas vozes se interiorizam no mesmo instante em que se mantêm distantes, isto é, há nesse fluxo permanência e destruição do próprio eu.

Em Spartakus, Furio Jesi escreve que o eu:

é o elemento comum, o ponto de intersecção entre dois universos: aquele da vida e do tempo histórico, aquele da morte e do tempo mítico... $\mathrm{O}$ eu que sofre o tempo histórico mesmo sendo partícipe do tempo mítico, no instante em que acede ao mito se expande como uma fonte, isto é, destrói-se num processo dinâmico que envolve sua duração histórica. $\mathrm{O}$ eu, em suma, é realmente partícipe do curso da história quando chega a identificar com esse o curso de sua destruição, e, portanto, de seu acesso ao mito. ${ }^{6}$

\footnotetext{
${ }^{4}$ Ibidem, p. 146.

${ }^{5}$ Ibidem, p. 146.

${ }^{6}$ JESI, Furio. Spartakus. Simbologia della rivolta. Org. Andrea Cavalletti. Torino: Bollati Boringhieri, 2000, p. 141-142.
} 
Importante ressaltar, aqui, que destruição, tal como a pensa Jesi, não significava morte como fim da vida, como bem destacou Andrea Cavalletti, em "Festa, scrittura, destruzione" - prefácio do livro Il tempo della festa - no qual Cavalletti argumenta que destruição deve ser pensada como "perda dos limites do eu individual no encontro com o mito", e que tal encontro, em Spartakus, "assume um sentido político: corresponde a um ato de insurreição que pode ser compreendido não como sacrifício da vida, mas como sacrifício e autodestruição das componentes burgueses do sujeito, no acesso ao outro e novo tempo do mito." ${ }^{7}$ Nesse sentido, podemos compreender melhor a investigação realizada por Jesi sobre a obra de Cesare Pavese.

Vale a pena nos determos um pouco sobre as primeiras impressões do ainda jovem Furio Jesi, quando, na escola, entrou pela primeira vez em contato com a literatura de Pavese, ou melhor, com um único poema do escritor, "I mari del Sud". Jesi, entre os anos 1951 e 1953, leu o poema de Pavese durante uma aula, com sua professora de literatura italiana, a qual falava de um amigo falecido há pouco tempo. Por isso, o poeta não representava ainda um daqueles monumentos intocáveis ou incompreensíveis a um jovem estudante, assim, Jesi teve a "possibilidade de lê-lo de modo crítico e curioso", e tal poema provocou uma certa ambivalência em seu modo de pensar, que naquela ocasião o estudante considerou como sendo uma impressão contraditória e negativa: "Por um lado, parecia-me um belo poema para ser lido, que dá gosto de ler; por outro, dava-me a impressão de um poema escrito por um homem que deseja ser um grande poeta, que deseja se tornar o grande poeta; que talvez não o seja." ${ }^{8}$ Jesi afirma que naquele momento Ihe provocava um certo incômodo o contraste entre a musicalidade dos versos, entre a épica e a lírica, ou seja, solene, e seu conteúdo que parecia estar aquém de seu mundo. Mas, ao mesmo tempo, o jovem leitor de Pavese encontrava também naqueles versos coisas cotidianas não "suficientemente lendárias ou remotas". Esse acontecimento lhe traz uma questão: "O jovem de então, do início dos anos 1950, não conseguia verdadeiramente entender o classicismo e a grandeza de $\mathrm{Pa}$ vese?" ${ }^{\prime \prime}$, visto que aquele jovem não tinha muita familiaridade com a literatura moderna e não conseguia aceitar a lírica anacrônica do poeta? Jesi nos diz que

\footnotetext{
${ }^{7}$ CAVALLETTI, Andrea. Festa, scrittura e distruzione. In: JESI, Furio. Il tempo della festa. Org. Andrea Cavalletti. Roma: Nottetempo, 2013, p. 16.

8 JESI, Furio. Il tempo della festa, op. cit., p. 119.

9 Ibidem, p. 121.
} 
"era certamente assim. Mas aprendi mais tarde que havia também alguma coisa de verdadeiro naquela primeira impressão crítica", e acrescenta:

Aprendi, sobretudo, a partir do momento em que comecei a confrontar como mitólogo a obra de Pavese, as relações de Pavese com o mito, e também com aquele que foi chamado de o 'mito de Pavese', o resultado da transfiguração mitológica da própria figura do escritor. ${ }^{10}$

Portanto, a parte de verdade que o jovem Jesi não conseguia explicar naquela fase de sua vida se mostra, depois, como o contraste "entre a convicção, que Pavese teve, ao reencontrar no repertório das imagens mitológicas um léxico poético imanente na natureza, e a escolha deliberada, que ele fez, de usar de um modo ou de outro aquele léxico." ${ }^{11}$ Essa concepção retoma a reflexão que se faz presente no início deste ensaio, ou seja, que o mito é desprovido de transcendência, ou ainda, que o mito é uma questão de linguagem. Pavese, segundo Jesi, acreditava no valor dos mitos como sistema de relações existentes na natureza. Não teria condição, aqui, de desdobrar toda a questão entre a existência na natureza de um sistema de relações e imagens mitológicas, porém cabe ressaltar que Pavese ligava tal existência a uma impossibilidade para o homem moderno de viver uma experiência coletiva do mito. Ao homem moderno é retirada a possibilidade de falar com a natureza, usando a linguagem da natureza que é aquela do mito. Na concepção de Jesi,

para Pavese os homens modernos não são mais capazes de experimentar todos juntos, intimamente, com a totalidade de seu ser, a veracidade objetiva e imanente na natureza do vocabulário da natureza. Com esse vocabulário, que é feito de imagens mitológicas, o homem moderno, seja ele poeta ou não, pode ter, no mais, relações individuais, mas não como membro de uma comunidade que é toda ela partícipe daquela riqueza. ${ }^{12}$

Desse modo, só lhe resta o mito do sacrifício, pois é "o único mito em que o indivíduo pode estar a sós em sua relação com a linguagem dos mitos, e apesar disso se une à sua comunidade porque deve estar sozinho, em base a uma lei que é aquela de sua comunidade", ${ }^{13}$ em última análise, "o mito do sacrifício

\footnotetext{
${ }^{10}$ Ibidem, p. 121.

${ }^{11}$ Ibidem, p. 121-122.

12 Ibidem, p. 125.

13 Ibidem, p. 125.
} 
é o único que permite ficar sozinho diante do mito, e em acordo com sua comunidade - em tempos nos quais o acesso comunitário ao mito é impossível." ${ }^{14}$

O mito do sacrifício é um mito de morte, no entanto, não desvinculado da própria vida. Ainda: o mito do sacrifício estabelece uma íntima relação com o problema da festa, ou melhor, com o tempo festivo. O paradigma com que Jesi confronta tal problema é justamente o da máquina mitológica. No ensaio "Cesare Pavese dal mito della festa al mito del sacrificio", escrito em 1966, Jesi analisa o "sentido da festa" na trilogia de Pavese: Bella estate (1940), Il diavolo sulle colline (1948) e Tra donne sole (1949). A festa é o paradigma dos três romances, a ausência com a qual as personagens se debatem, visto que não há mais a festa que confere valor à experiência coletiva, na qual os símbolos da morte, da terra, por exemplo, eram descobertos como uma verdadeira realidade. Porém, como destaca Jesi,

nas aventuras dos personagens de Pavese o mito não está ausente, pois em $\mathrm{Pa}$ vese não faltou o "sentido de festividade", porém a relação com o mito está garantida não pela participação às realidades da festa, mas, sim, pela submissão à lei que forçava os "heróis" a procurarem o tesouro, e que se configura como lei moral. $^{15}$

No entanto, a máquina mitológica implica a impossibilidade para o eu do escritor de aceder à própria festa. No ensaio "Cognoscibilidade da festa", Jesi escreve:

Quando a festa não é mais possível, pois não existem mais os pressupostos sociais e culturais para uma experiência da coletividade que "no mais profundo" seja "mais semelhante à alegria que à melancolia", a memória da festa antiga e perdida assume numa nostalgia um sobressalto tão nítido que atrai no âmbito da "festa" em negativo, da forma em concavidade, toda experiência que seja coletiva, dolorosa, e que em alguma medida corresponda - exatamente em negativo - às características da verdadeira festa. ${ }^{16}$

Se a verdadeira festa não é mais possível, então essa perda impõe o sacri-

\footnotetext{
${ }^{14}$ Ibidem, p. 126.

${ }^{15}$ JESI, Furio. Cesare Pavese dal mito della festa al mito del sacrificio. In: Letteratura e mito. Torino: Einaudi, 1968, p. 164-165. O texto foi publicado originalmente como introdução de La bella estate, de Cesare Pavese, na série "Nuova Universale Einaudi", Torino, 1966.

${ }^{16} \mathrm{JESI}$, Furio. Conoscibilità della festa, In: /l tempo della festa, op. cit., p. 66.
} 
fício como horizonte e fundamento do agir, e este se torna para o escritor o próprio ato de criação. Este se dá a partir de uma obrigação moral que transforma o presente no lugar e no tempo do mito. Em Cesare Pavese, segundo a concepção de Jesi, "a recusa da narrativa abertamente fantástica e a vontade de envolver na esfera do mito os acontecimentos e as presenças do hoje" ${ }^{17}$ estabelecem um vínculo entre mito e moral, entre comportamento e sacrifício humano, criando uma genuína epifania mítica do real. Em seu diário - 11 mestiere di vivere -, no dia 17 de setembro de 1943, Pavese escreve: "O lugar mítico não é aquele individualmente único, tipo santuário ou coisa semeIhante, mas, sim, aquele de nome comum, universal, o prado, a selva, a gruta, a praia, a clareira, que em sua indeterminação evoca todos os prados, as selvas, etc." ${ }^{18}$, ou seja, lugar em que as realidades das antigas festas jazem latentes e, ao mesmo tempo, lugar em que os homens não podem mais participar de uma coletiva epifania de verdade. Como operar a máquina mitológica se no ato de criação se interpõe uma resistência? Talvez, compreendendo de um novo modo a relação íntima existente entre criação e resistência. Giorgio Agamben, em "Che cos'è l'atto di creazione?" - retomando a questão e a reflexão de Gilles Deleuze, conferência realizada pelo filósofo francês em Paris, em 1987 - procura definir melhor por que o ato de criação é um "ato de resistência", visto que "Deleuze não define o que significa 'resistir' e parece dar ao termo o significado corrente de opor-se a uma força ou a uma ameaça exterior". ${ }^{19}$ Agamben, mais adiante em seu texto, define seu modo de pensar a relação entre criação e resistência:

Há, em todo ato de criação, algo que resiste e se opõe à expressão. Resistir, do latim sisto, significa etimologicamente "deter, manter parado" ou "deter-se". Esse poder que mantém e detém a potência em seu movimento em direção ao ato é a impotência, a potência-de-não. Ou seja, a potência é um ser ambíguo, que não só pode tanto uma coisa que seu contrário, mas contém em si mesma uma íntima e irredutível resistência. ${ }^{20}$

Nessa perspectiva, podemos compreender melhor a noção de tempo festivo tanto em Jesi quanto em Pavese: é o tempo que não é mais e que, mesmo

\footnotetext{
${ }^{17}$ JESI, Furio. Cesare Pavese dal mito della festa al mito del sacrificio, op. cit., p. 168.

${ }^{18}$ PAVESE, Cesare. Il mestiere di vivere. Torino: Giulio Einaudi, 1975, p. 244.

19 AGAMBEN, Giorgio. Che cos'è l'atto di creazione. In: Il fuoco e il racconto. Roma: Nottetempo, 2014, p. 39.

${ }^{20}$ Ibidem, p. 46.
} 
assim, resiste, não como potência, mas como potência-de-não: em última análise, na narrativa de Pavese - seu ato de criação e resistência - a perda da festa não significa sua ausência absoluta, mas, sim, sua resistência, pois em Pavese, como bem destacou Jesi, "não faltou o sentido de festividade". ${ }^{21}$

${ }^{21} \mathrm{JESI}$, Furio. Cesare Pavese dal mito della festa al mito del sacrificio, op. cit., p. 164. 